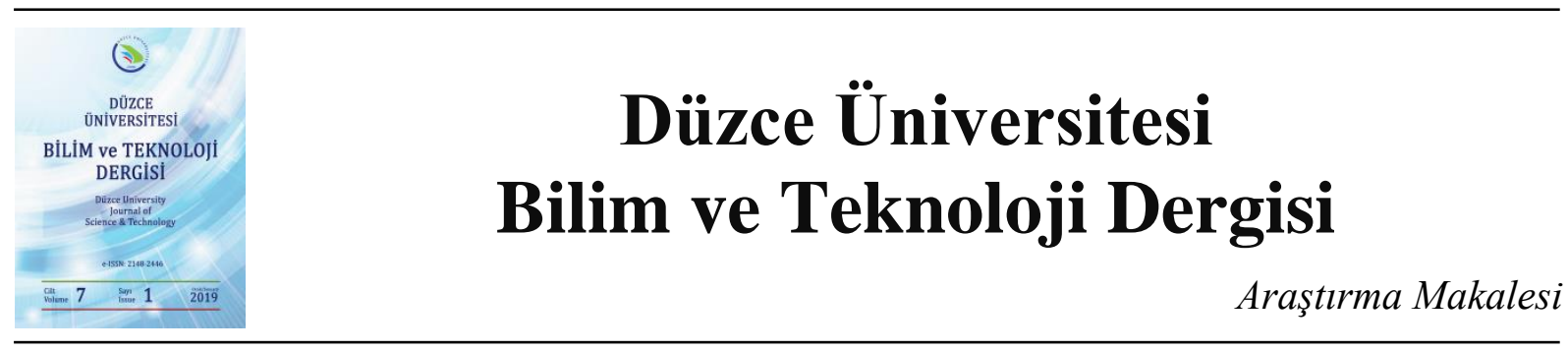

\section{Çelik Tel Örgülerin Betonarme Kirişlerin Kesme Davranışına Etkisi}

\author{
Serhat DEMIR ${ }^{\mathrm{a}, *}$ \\ ${ }^{a}$ İnşaat Mühendisliği Bölümü, Mühendislik Fakültesi, Karadeniz Teknik Üniversitesi, Trabzon, TÜRKIYYE \\ * Sorumlu yazartn e-posta adresi: s.demir@ktu.edu.tr
}

\begin{abstract}
ÖZET
Çelik tel örgülerin çimento hamuruyla birlikte uygulanması neticesinde meydana gelen ferro-çimento, mevcut betonarme yapı elemanlarının güçlendirilmesinde kullanılan bir yöntemdir. Bu çalışmada ise, çelik tel örgülerin kesme donatısı olarak kullanılmasının betonarme kirişlerin davranışlarına etkileri deneysel olarak araştııılmıştır. Bunun için $150 * 300 * 2000 \mathrm{~mm}$ ebatlarında ve farklı donatı düzenine sahip üç adet betonarme kiriş üretilerek dört nokta eğilme testine tabi tutulmuştur. Sonuçta, çelik tel örgülerin kirişin çatlama mekanizmasını iyileştirerek geniş çatlakları azaltıp kılcal çatlakları artırdığı görülmüştür. Ancak, kesme donatısı olarak yalnızca çelik tel örgü kullanımı çatlamış kirişte erken dayanım kaybına neden olmuştur. Kesme donatısı olarak etriyelere ilaveten çelik tel örgülerin kullanılması durumunda ise betonarme kirişlerin yük taşıma kapasiteleri, başlangıç rijitlikleri ve yerdeğiştirme süneklikleri önemli oranda artmıştır.
\end{abstract}

Anahtar Kelimeler: Çelik tel örgü, Dört nokta eğilme deneyi, Betonarme kiriş

\section{Effect of The Steel Wired Mesh On the Shear Behavior of RC Beams}

\begin{abstract}
Ferro-cement made of steel wired mesh and cement mortar is a method using for strengthening of existing reinforced concrete structures. In this study, the effects of the steel wired mesh on the shear behavior of reinforced concrete beams were investigated experimentally. For this purpose, three reinforced concrete beams having 150x300×2000 mm dimensions and different reinforcements were produced and subjected to four point bending tests. As a result, steel wired mesh improved the cracking mechanism of the beam by reducing the number of large cracks while increasing minor cracks. However, the use of steel wired mesh has caused early strength loss of the cracked beam. In the case of the usage of steel wired mesh in addition to the stirrups as shear reinforcement, the load bearing capacities, initial stiffness and displacement ductility of the reinforced concrete beams have significantly increased.
\end{abstract}

Keywords: Steel wired mesh, Four point bending test, Reinforced concrete beam 


\section{GiRiș}

A ni ve gevrek kesme kırılmaları betonarme yapı elemanları için en temel problemlerden birisidir. $\mathrm{Bu}$ problem asal çekme gerilmelerinin betonun çekme dayanımını aşması neticesinde diyagonal geniş çatlakların meydana gelmesi ile oluşur [1]. Yetersiz sargılama, $90^{\circ}$, lik gönye, aşırı yükleme, kalitesiz malzeme ve işçilik gibi nedenlerle geçmişte yaşanılan depremlerde birçok yapı elemanında ani ve gevrek kesme göçmesi yaşanmıştır [2,3]. Bu nedenle, bugün, mevcut yönetmelikler [4-6] kesme güvenliğini sağlamak için kritik bölgelerde etriye sıkılaştırmasını şart koşmaktadır. Yapılarda tamamen göçmenin engellenmesi için kolonların kirişlere göre güçlü tasarlanması [7], ve sünek davranış için plastik mafsalların kiriş uçlarında oluşması istenmektedir. Kirişlerin tasarımında etkili sargılama ve lif kullanımı ile sünekliğin artırılabileceği bilinmektedir [8-10]. Bununla birlikte, mevcut betonarme yapı elemanlarının kesme davranışları FRP, ferro-çimento veya çelik sargılama ile iyileştirilebilmektedir [11-16].

Takiguchi $[11,12]$ kesme dayanımı yetersiz kolonların yerdeğiştirme sünekliliklerinin ferro-çimento sargılama ile belirgin miktarda artırılabileceğini göstermiştir. Nassif ve Najm [13] yaptıkları deneysel ve analitik çalışmalarda ferro-çimento ile güçlendirdikleri kirişleri göçme anına kadar dört nokta yükleme testine tabi tutmuşlardır. Sonuçta, test edilen kompozit kirişlerin süneklik, çatlama dayanımı ve eksenel yük taşıma kapasiteleri bakımından normal kirişlere göre daha yüksek performans sergiledikleri görülmüştür. Bansal ve diğerleri [14] ferro-çimento ile güçlendirdikleri kirişlerde tel örgü açısının 45 ile 60 derece olması durumunda yük taşıma ve enerji yutma kapasitesinin önemli oranda arttı̆̆ını göstermişlerdir.

Çelik tel örgülerin (ÇTÖ) çimento hamuru ile birlikte uygulanması ile meydana gelen ferro-çimento genel olarak yapı elemanlarını dıştan sargılayarak güçlendirmede kullanılmaktadır. Bu çalışmada ise ÇTÖ' lerin betonarme kirişlerde kesme donatısı olarak kullanılması ile kirişlerin kesme kapasitesinin artırılması amaçlanmıştır. Bu doğrultuda üretilen 3 farklı deney elemanı dört nokta eğilme testine tabi tutulmuştur. Deneyler boyunca yük-yerdeğiştirme ilişkileri ve donatılardaki birim şekildeğiştirmeler kaydedilmiş olup betonun çatlama mekanizması gözlemlenmiştir.

\section{MATERYAL ve Metot}

\section{A. KULLANILAN MALZEMELER ve ÖZELLIKLERI}

Deney elemanlarının üretiminde kullanılacak betonda CEM II/A-P $32.5 \mathrm{~N}$ tipi çimento ile maksimum tane çapı $12 \mathrm{~mm}$ olan kalker agregası kullanılmıştır. Kullanılan agregaların bazı fiziksel özellikleri Tablo 1' de verilmiştir. Üretilmesi planlanan betonun karışım oranı Tablo 2' de verilmiştir. Bu karışım oranına göre hazırlanan betondan kalıplara döküm işlemi esnasında üçer adet $150 \mathrm{~mm}$ çapında ve 300 mm yüksekliğinde standart silindir basınç numunesi alınmıştır. Bu numuneler 28 gün boyunca kür havuzunda bekletildikten sonra merkezi basınç testine tabi tutulmuş olup ortalama basınç dayanımları $23.1 \mathrm{MPa}$ dır ( Tablo 2 ). Deney elemanların üretiminde 8 ve $12 \mathrm{~mm}$ çaplarında nervürlü donatılar kullanılmıştır. $\mathrm{Bu}$ donatılardan alınan üçer adet numune üzerinde gerçekleştirilen merkezi çekme deneyleri neticesinde akma dayanımları ortalama 496.2 ve $517.7 \mathrm{MPa}$ olarak belirlenmiştir. Kullanılan ÇTÖ' lerin örgü aralıkları $25 \mathrm{~mm}$, tel çapı ise $2.0 \mathrm{~mm}$ ' dir (Şekil 1). ACI 549 [17]' a uygun olarak yapılan çekme deneylerinde ÇTÖ' nün ortalama akma dayanımı 173.7 MPA olarak belirlenmiştir. 
Tablo 1. Agrega fiziksel özellikleri

\begin{tabular}{lccc}
\hline $\begin{array}{c}\text { Agrega } \\
\text { Boyutu }\end{array}$ & $\begin{array}{c}\text { Kuru Birim } \\
\text { Kütle } \\
\left(\mathrm{kg} / \mathrm{m}^{3}\right)\end{array}$ & $\begin{array}{c}\text { Doygun Birim } \\
\text { Kütle } \\
\left(\mathrm{kg} / \mathrm{m}^{3}\right)\end{array}$ & $\begin{array}{c}\text { Su Emme } \\
(\%)\end{array}$ \\
\hline İri $(4-12 \mathrm{~mm})$ & 2706 & 2720 & 0.43 \\
\hline İnce $(0-4 \mathrm{~mm})$ & 2675 & 2682 & 0.50 \\
\hline
\end{tabular}

Tablo 2. Beton karışım oranı ile ortalama basınç dayanımı

\begin{tabular}{ccccccc}
\hline & $\mathbf{S} / \mathbf{C}$ & $\begin{array}{c}\text { Çimento } \\
\left(\mathrm{kg} / \mathrm{m}^{3}\right)\end{array}$ & $\begin{array}{c}\text { Su } \\
\left(\mathrm{kg} / \mathrm{m}^{3}\right)\end{array}$ & $\begin{array}{c}\text { İri } \\
\text { agrega } \\
\left(\mathrm{kg} / \mathrm{m}^{3}\right)\end{array}$ & $\begin{array}{c}\text { Ince } \\
\text { agrega } \\
\left(\mathrm{kg} / \mathrm{m}^{3}\right)\end{array}$ & $\begin{array}{c}\text { Ortalanma basınç } \\
\text { dayanımı } \\
(\mathrm{MPa})\end{array}$ \\
\hline $\begin{array}{c}\text { Geleneksel } \\
\text { beton }\end{array}$ & 0.50 & 362 & 181 & 1012 & 742 & 23.1 \\
\hline
\end{tabular}

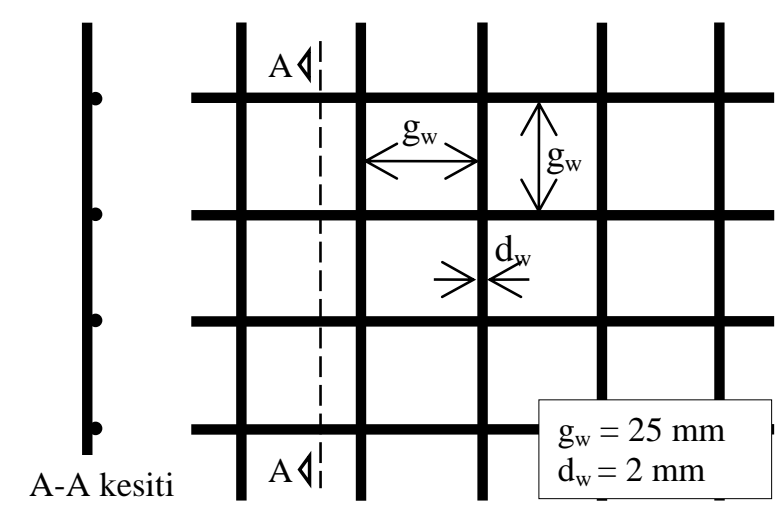

Şekil 1. Kullanılan ÇTÖ' nün boyutları

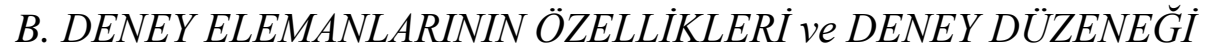

Deneysel çalışmalar kapsamında boyutları 150x300x2000 mm olan üç farklı betonarme kiriş üretilerek test edilmiştir. B1 olarak isimlendirilen ilk deney elemanı geleneksel bir betonarme kirişi temsil etmektedir. $\mathrm{Bu}$ deney elemanında boyuna ve enine donatı olarak sırasıyla 12 ve $8 \mathrm{~mm}$ çaplarında nervürlü donatılar kullanılmıştır. B2 isimli deney elemanında B1 ile aynı boyuna donatılar kullanılırken enine donatı olarak yalnızca ÇTÖ kullanılmıştır. B3 isimli deney elemanında ise B1'de kullanılan enine ve boyuna donatıya ilave olarak ÇTÖ kullanılmıştır. ÇTÖ boyuna ve enine donatıyı dıştan saracak şekilde uygulanmıştır. Donatıları hazırlanan deney elemanları Şekil 2 'de, donatı detayları ise Şekil 3' de gösterilmiştir.

Deney elemanları Şekil 4' de gösterilen basit mesnetli dört nokta eğme deney düzeneğine yerleştirilerek test edilmiştir. Yüklemeler yerdeğiştirme kontrollü bir hidrolik piston ile gerçekleştirilmiştir. Deneyler esnasında hidrolik pistonun ucuna yerleştirilen $500 \mathrm{kN}$ kapasiteli bir yük 
hücresi ile yük ölçümleri yapılmıştır. Kiriş alt açılığı boyunca yerleştirilen 5 adet potansiyometrik cetvel (LPDT) vasıtası ile yerdeğiştirme ölçümleri gerçekleştirilmiştir. Ayrıca, her deney elemanında birer adet boyuna donatıya birim şekildeğiştirme ölçer yapıştırılarak bu donatılardaki birim uzamalar ölçülmüştür. Ölçümler Coda AI8b veri toplama cihazı ile kayıt altına alınmıştır.

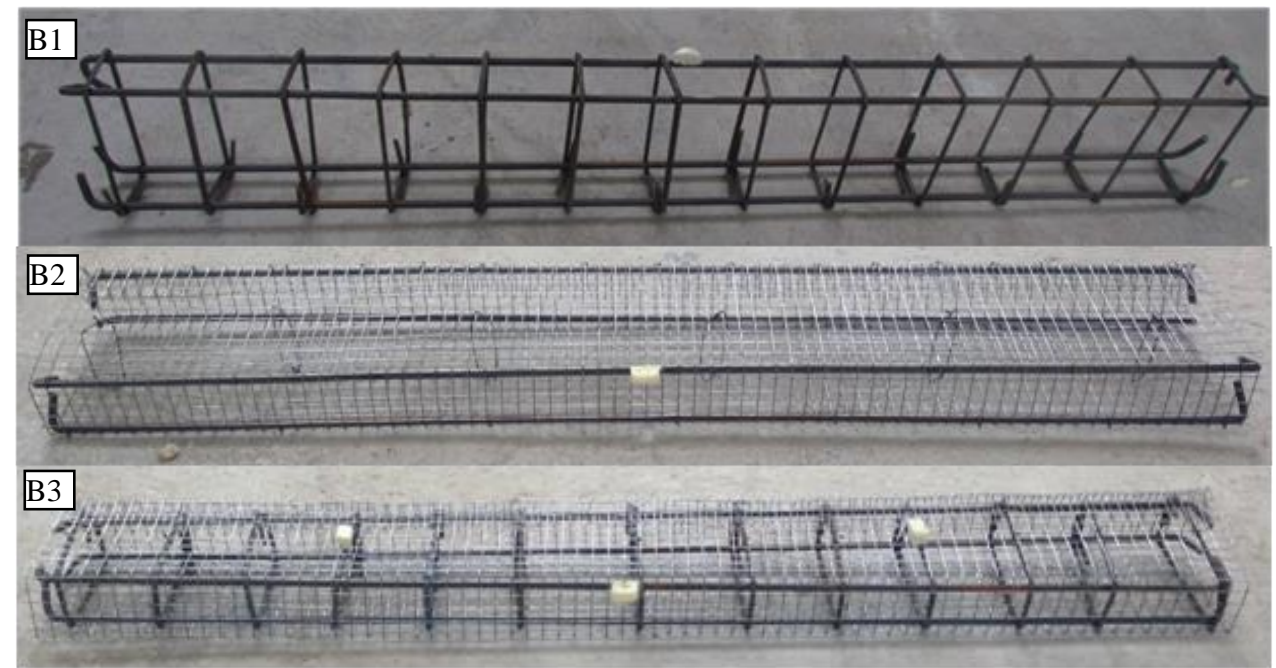

Şekil 2. Deney elemanlart

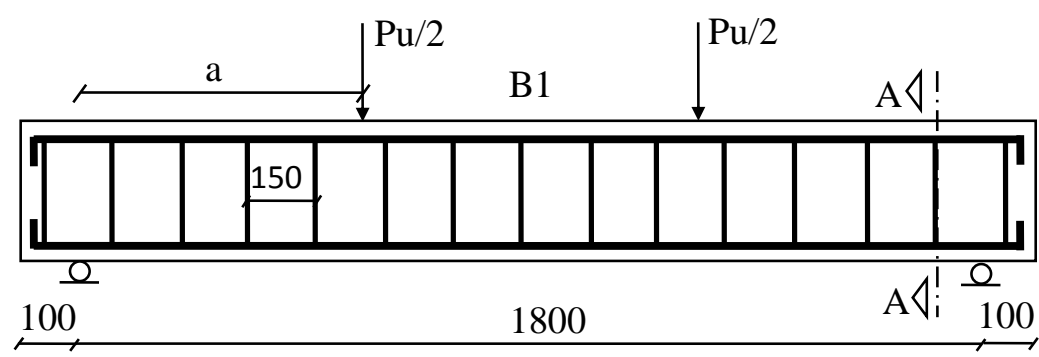

A-A Kesiti
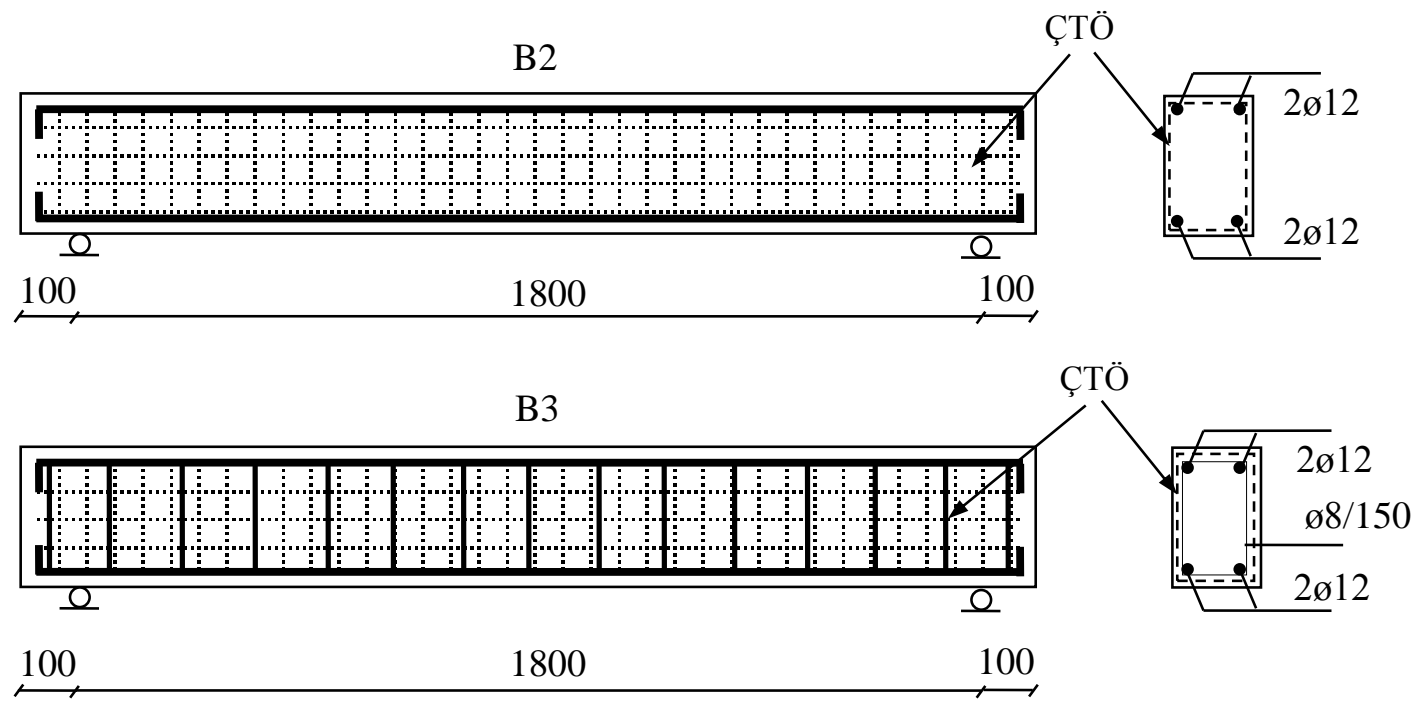

Şekil 3. Deney elemanlarınin boyutlart ve donatı detayı. 


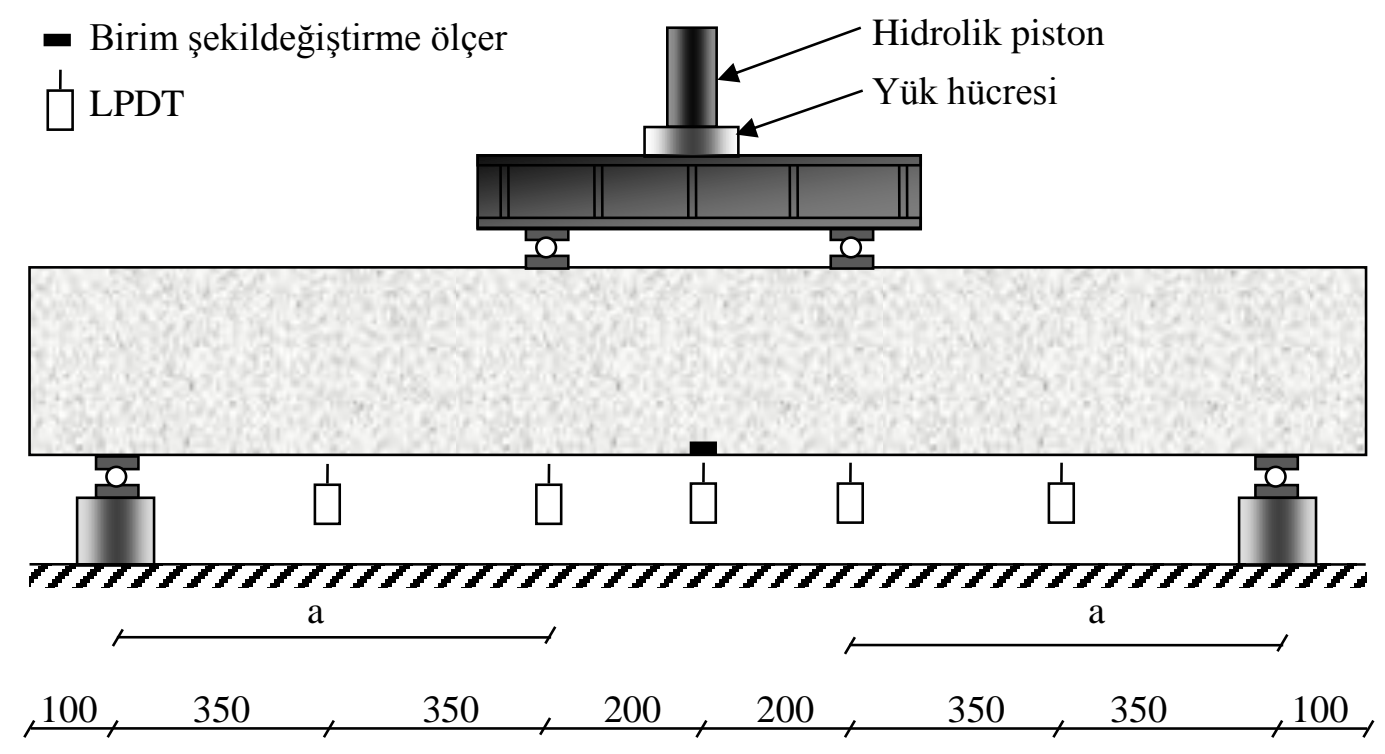

Şekil 4. Deney düzeneği

\section{KESME AÇIKLIĞININ BELIRLLENMESI}

Bugüne kadar betonun kesme davranışını belirleyebilmek için birçok çalışma yapılmıştır [18-20]. Kani kesme açıklığının (a) faydalı yüksekliğe (d) oranının (a/d) betonarme kirişlerin davranışını etkileyen en önemli faktörlerden biri olduğunu göstermiş ve kirişler için bağıl eğilme kapasitesinin $\left(\mathrm{M}_{\mathrm{u}} / \mathrm{M}_{\mathrm{fl}}\right)$ a/d'ye göre değişimini gösteren bir "Kesme vadisi”' belirlemiştir [18]. Kesme etkisindeki kirişlerde nihai moment $\left(\mathrm{M}_{\mathrm{u}}\right)$ aşağıdaki gibi hesaplanmıştır [20]:

$M_{u}=V_{u} a$

$V_{u}=\frac{P_{u}}{2}=v_{u} b d$

$v_{u}=\left[\frac{\sqrt[3]{\rho}}{\left(1+\frac{d}{25 d_{a}}\right)^{1 / 2}}\right]\left[0.83 \sqrt{f_{c}^{\prime}}+206.9 \sqrt{\frac{\rho}{(a / d)^{5}}}\right] b d$

burada $\mathrm{V}_{\mathrm{u}}$ kirişin etkiyen kesme yükü, $\mathrm{Pu}$ kirişe etkiyen toplam yük, $v_{\mathrm{u}}$ kirşin kesme dayanımı, $\rho$ boyuna donatı oranı, $\mathrm{d}$ faydalı yükseklik, $f^{\prime}$ c betonun basınç dayanımı and $\mathrm{d}_{\mathrm{a}}$ maksimum agrega boyutudur. Kirişin eğilme kapasitesi $\left(\mathrm{M}_{\mathrm{fl}}\right)$ ise ACI 318 [4]' e göre aşağıdaki gibi hesaplanmıştır.

$\mathrm{M}_{\mathrm{fl}}=b d^{2} \rho f_{y}\left(1-\frac{\rho f_{y}}{1.7 f_{c}^{\prime}}\right)$

burada $f_{\mathrm{y}}$ boyuna donatının akma dayanımıdır. 
Deneye tabi tutulacak kirişler için hesaplanan "Kesme vadisi', Şekil 5'de gösterilmiştir. Bu şekilde görüldüğü gibi iki göçme modu arasındaki (kesmede ezilme ve eğik çekme) geçiş noktası $(\mathrm{a} / \mathrm{d}) \mathrm{T}=$ 2.0'dır. Deneylerde eğik çekme kırılması göz önünde bulundurularak a/d=2.7 olacak şekilde kesme açıklığı seçilmiştir. Bu doğrultuda kirişlere uygulanacak tekil simetrik yükler, kesme açıklığı $700 \mathrm{~mm}$ olacak şekilde, mesnetlerden $700 \mathrm{~mm}$ uzaklıkta uygulanmıştır (Şekil 4).

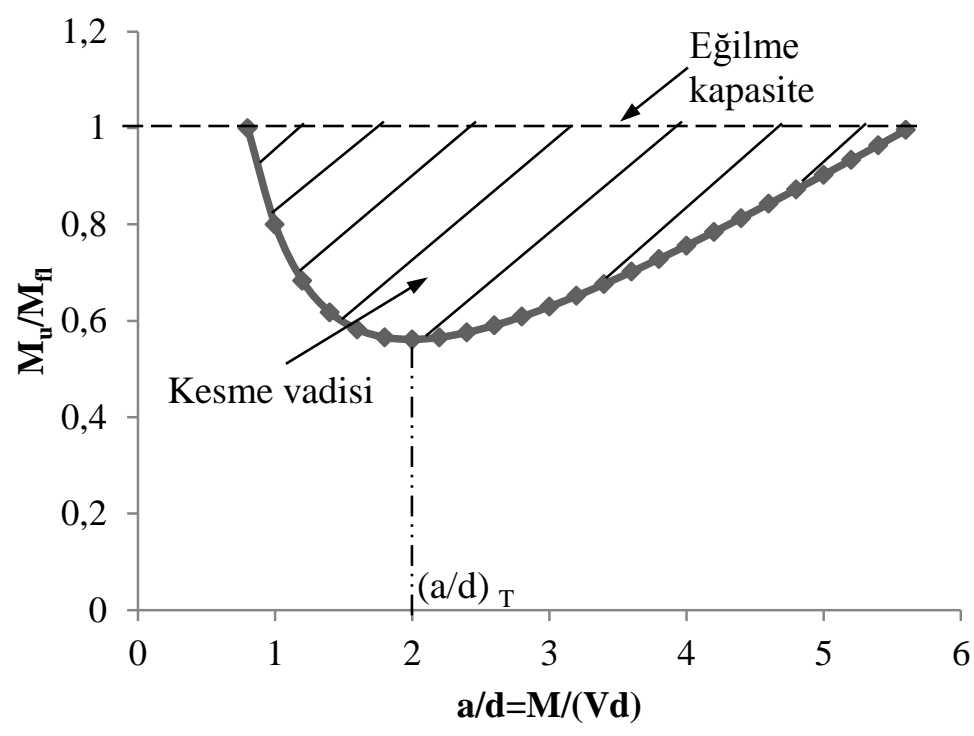

Şekil 5. Deney elemanlarına göre hesaplanan kesme vadisi.

\section{BULGULAR}

Deneylerden elde edilen yük-yerdeğiştirme eğrileri Şekil 5'de sonuçlar ise Tablo 3'de özetlenmiştir. Geleneksel betonarme kirişleri temsil eden B1 isimli deney elemanından 7.6 mm' lik yerdeğiştirmede boyuna donatı akma birim şekildeğiştirmesine ulaşmıştır. 10.33 mm'lik yerdeğiştirmede ve $89.63 \mathrm{kN}$ yük seviyesinde ise kiriş akma yüküne ulaşırken başlangıç rijitliği $8.68 \mathrm{kN} / \mathrm{mm}$ olarak hesaplanmıştır. Akma yüküne kadar kiriş boyunca meydana gelen kılcal çatlaklar artan yerdeğiştirmelerle giderek genişlemişlerdir. Nihai durumda, B1 kirişi $103.44 \mathrm{kN}$ yük taşırken 44.03 mm'lik yerdeğiştirmede göçme meydana gelmiştir. Yerdeğiştirme sünekliliği 4.26 olarak hesaplanmıştır.

Kesme donatısı olarak yalnızca ÇTÖ'nün kullanıldığı B2 numunesinde boyuna donatı 7.95 mm'lik yerdeğiştirmede akma birim şekildeğiştirmesine ulaşmıştır. 10.89 mm'lik yerdeğiştirmede ve 110.13 $\mathrm{kN}$ yük seviyesinde $\mathrm{B} 2$ kirişi akma yüküne ulaşmıştır. Başlangıç rijitliği $10.11 \mathrm{kN} / \mathrm{mm}$ olarak hesaplanmıştır. 113.37 kN'luk maksimum yüke 17.30 mm'lik yerdeğiştirmede ulaşmıştır. Akma yüküne kadar B1 kirişine benzer bir çatlak yayılımı gösteren B2 kirişinde akma yükünden sonra çatlaklardaki genişlemeler B1 kirişine göre daha az olsa da, 25.45 mm'lik yerdeğiştirmede eğik çekme çatlakları aniden genişleşmiş ve göçme yaşanmıştır. Yerdeğiştirme sünekliliği 2.33 olarak hesaplanmıştır.

B3 numunesinde ÇTÖ ile kesme donatısının birlikte kullanılması ile B1 ve B2 numunelerine göre hem daha rijit hem de daha sünek bir davranış elde edilmiştir. Henüz 4.9 mm'lik yerdeğiştirmede boyuna donatı akma birim şekildeğiştirmesine ulaşmıştır. Akma yüküne 6.86 mm'lik yerdeğiştirmede ve 
115.35 kN yük seviyesinde ulaşılırken başlangıç rijitliği ve yerdeğiştirme sünekliliği sırasıyla 16.81 $\mathrm{kN} / \mathrm{mm}$ ve 6.28 olarak elde edilmiştir. Maksimum yük $122.98 \mathrm{kN}$ olarak elde edilirken, numune yük taşıma kapasitesini 43.10 mm'lik yerdeğiştirmede kaybetmiştir.

Tablo 3. Deney sonuçlart

\begin{tabular}{ccccccc}
\hline $\begin{array}{c}\text { Deney } \\
\text { elemanı }\end{array}$ & $\begin{array}{c}\mathbf{P}_{\mathbf{y}} \\
(k N)\end{array}$ & $\begin{array}{c}\boldsymbol{\delta}_{\mathbf{y}} \\
(\mathrm{mm})\end{array}$ & $\begin{array}{c}\mathbf{P}_{\mathbf{m a x}} \\
(k N)\end{array}$ & $\begin{array}{c}\boldsymbol{\delta}_{\mathbf{m a x}} \\
(\mathrm{mm})\end{array}$ & $\begin{array}{c}\mathbf{K}_{\mathbf{y}}{ }^{*} \\
(\mathrm{kN} / \mathrm{mm})\end{array}$ & $\boldsymbol{\mu}_{\mathbf{y}}{ }^{* * *}$ \\
\hline $\mathrm{B} 1$ & 89.63 & 10.33 & 103.44 & 44.03 & 8.68 & 4.26 \\
\hline $\mathrm{B} 2$ & 110.13 & 10.89 & 113.37 & 25.45 & 10.11 & 2.33 \\
\hline $\mathrm{B} 3$ & 115.35 & 6.86 & 122.98 & 43.10 & 16.81 & 6.28 \\
$\begin{array}{c}\text { ::Başlangıç rijitliği: } \mathrm{K}_{\mathrm{y}}=\mathrm{P}_{\mathrm{y}} / \delta_{\mathrm{y}} \\
\text { ** }: \text { Yerdeğiştirme sünekliliği: } \mu_{\mathrm{y}}=\delta_{\max } / \delta_{\mathrm{y}}\end{array}$ & & & & \\
\end{tabular}

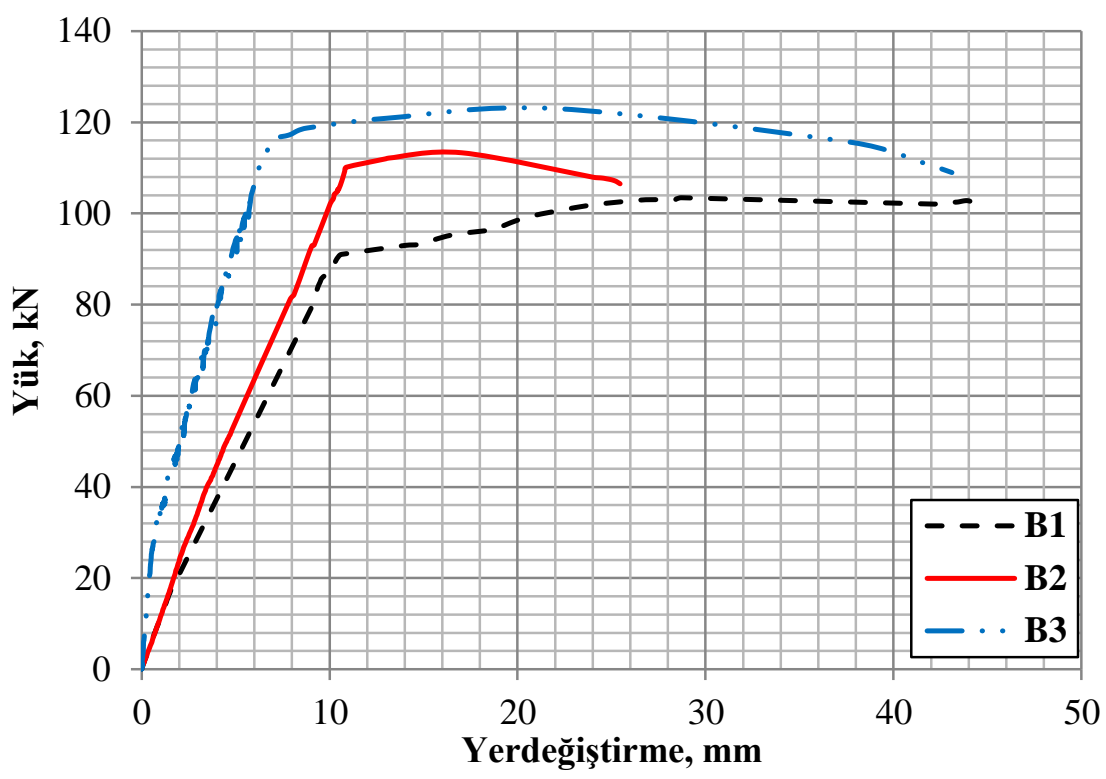

Şekil 5. Yük-yerdeğiştirme ĕgrileri

Deneyler esnasında boyuna donatılarda meydana gelen birim şekildeğiştirme değerleri Şekil. 6'da gösterilmiştir. B1 ve B2 numunelerinde boyuna donatılarda meydana gelen birim şekildeğiştirmeler birbirine çok benzerdir. B3 numunesindeki boyuna donatıda ise diğer deney elemanlarına göre çok daha büyük şekildeğiştirmeler meydana gelmiş ve nihai durumda boyuna donatının kopması ile göçme yaşanmıştır (Şekil 8). 


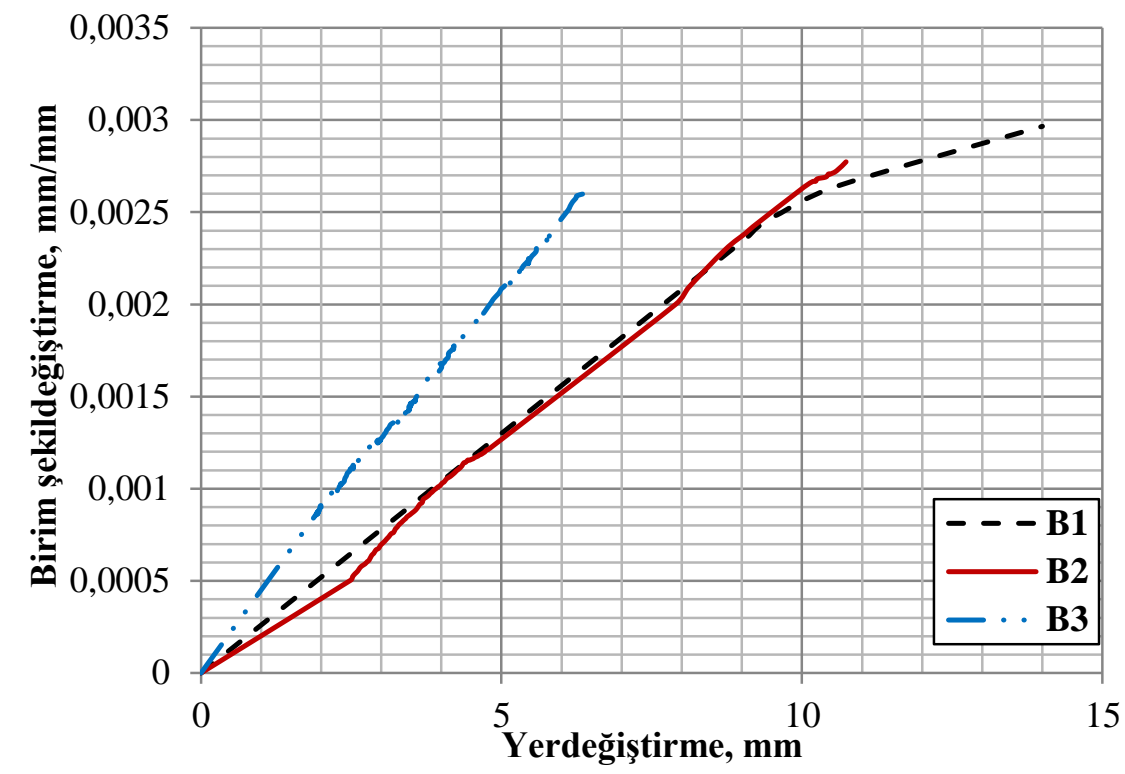

Şekil 6. Boyuna donatılarda meydana gelen birim şekildeğiştirmeler

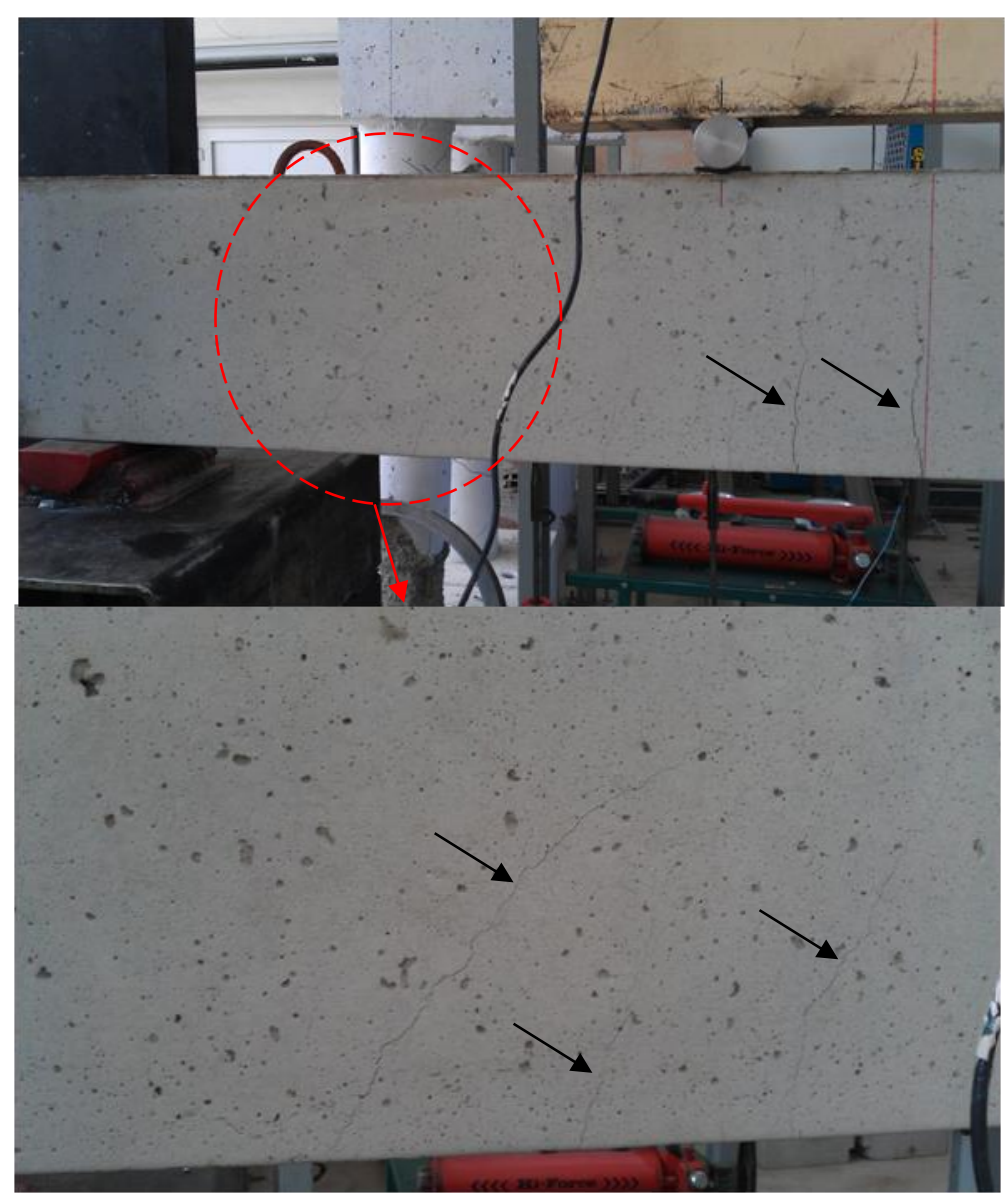

Şekil 7. B3' de meydana gelen kilcal çatlaklar 


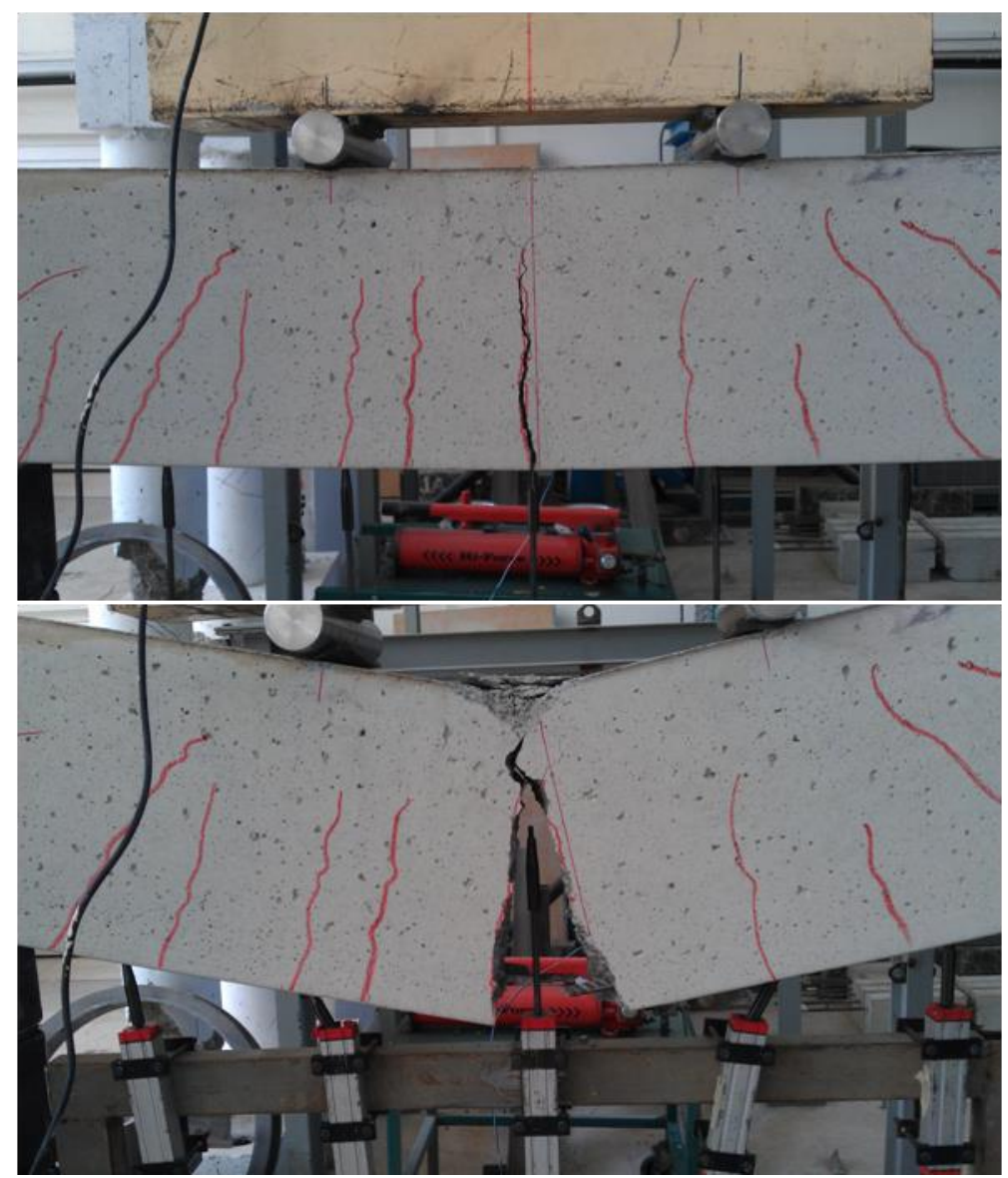

Şekil 8. B3 numunesinin göçme anı

\section{SONUCLAR}

$\mathrm{Bu}$ çalışmada, kesme donatısı olarak ÇTÖ kullanılan betonarme kirişlerin davranışları deneysel olarak araştırılmıştır. Elde edilen başlıca sonuçlar aşağıdadır:

- Kesme donatısı olarak etriye yerine çelik tel örgülerin kullanılması durumunda kirişte meydana gelen geniş çatlakların sayısı azalmakta kılcal çatlakların sayısı ise artmaktadır. Ancak, çelik tel örgülerin sargılama dayanımının düşük olması çatlamış kirişin daha kolay yerdeğiştirme yapmasına ve dayanımını erkenden kaybetmesine neden olmaktadır.

- Etriye ile çelik tel örgülerin birlikte kullanılması durumunda, meydana gelen çatlaklar kılcal seviyede kalırken etriyenin sağladığı yüksek sargılama etkisi çatlamış kirişin yerdeğiştirme yapmasını zorlaştırarak göçmeyi geciktirmektedir.

- Çelik tel örgü ile etriyenin birlikte kullanıldığı durum yalnızca etriyenin kullanıldığı duruma göre çok daha iyi bir sargılama etkisi sağlamaktadır. Böylece, başlangıç rijitliği ve yerdeğiştirme sünekliliğin de önemli artışlar meydana gelmektedir.

- Çelik tel örgülerde tellerin hem enine hem boyuna doğrultuda örülü olması kirişlerin yük taşıma kapasitesini artırmaktadır. 


\section{$\underline{\text { V. KAYNAKLAR }}$}

[1] A. Cladera and A. R. Mari, "Experimental study on high-strength concrete beams failing in shear," Engineering Structures, vol. 27, pp. 1519-1527, 2005.

[2] EERI Special Earthquake Report, "The Izmit (Kocaeli), Turkey earthquake of August 17, 1999," EERI, California, 1999.

[3] EERI Special Earthquake Report, "The mw 7.1 Erciş-Van, Turkey earthquake of October 23, 2011," EERI, California, 2012.

[4] Building Code Requirements for Structural Concrete (ACI 318-02) and Commentary (ACI 318R-02), American Concrete Institute, 2002.

[5] Design of Structures for Earthquake Resistance, EN 1998-1 -Part 1: General Rules, Seismic Actions and Rules For Buildings, CEN, 2004.

[6] Deprem Bölgelerinde Yapılacak Binalar Hakkında Yönetmelik, Bayındırlık ve İskan Bakanlığı, 2007.

[7] L. S. Beedle and D. B. Rice, Structural Systems For Tall Buildings, New York, USA: McGraw-Hill, 1995.

[8] C. Cucchiara, L. L. Mendola and M. Papia, "Effectiveness of stirrups and steel fibres as shear reinforcement," Cement and Concrete Composites, vol. 26, pp. 777-786, 2004.

[9] A. Ding, Y. Zhiguo and J. Said, "The composite effect of steel fibres and stirrups on the shear behaviour of beams using self-consolidating concrete," Engineering Structures, vol. 33, pp. 107-117, 2011.

[10] G. Russo, D. Mitri and M. Pauletta, "Shear strength design for rc beams with stirrups," Engineering Structures, vol. 51, pp.226-235, 2013.

[11] K. Takiguchi and Abdullah, "Shear strengthening of rc columns with ferrocement," ACI Structural Journal, vol. 98, no. 5, pp. 696-704, 2001.

[12] Abdullah and K. Takiguchi, "An investigation into the behaviour and strength of reinforced concrete columns strengthened with ferrocement jackets," Cement and Concrete Composites, vol. 25, pp. 233-242, 2003.

[13] H. H. Nassif and H. Najm, "Experimental and analytical investigation of ferrocement-concrete composite beams," Cement and Concrete Composites, vol. 24, pp. 787-796, 2004.

[14] P. P. Bansal, M. Kumar and S. K. Kaushik, "Effect of wire mesh orientation on strength of beams retrofitted using ferrocement jackets," International Journal of Engineering, vol. 2, no. 1, pp. 8-19, 2006. 
[15] M. J. Chajes, T. F. Januska, D. R. Mertz, T. A. Thomson and W. W. Finch, "Shear strengthening of reinforced concrete beams using externally applied composite fabrics," $A C I$ Structural Journal, vol. 92, no. 3, pp. 295-303, 1995.

[16] T. C. Triantafillou, "Shear strengthening of reinforced concrete beams using epoxy-bonded frp composites," ACI Structural Journal, vol. 95, no. 2, pp. 107-115, 1998.

[17] Guide for Design, Construction and Repair of Ferrocement, American Concrete Institute, ACI Committee 549 (ACI 549.1R-93), 1993.

[18] G. N. J. Kani, " Basic facts concerning shear failure," ACI Journal Proceedings, vol. 63, no. 6, pp. 675-692, 1966.

[19] C. Z. Theodore, "Shear strength prediction for separate categories of simple beam test," ACI Journal Proceedings, vol. 68, no. 15, pp. 138-143, 1971.

[20] Z. P. Bažant and J. K. Kim, "Size effect in shear failure of longitudinally reinforced beams," ACI Journal Proceedings, vol. 81, no. 5, pp. 456-468, 1984. 